\title{
CHANGES IN ESTONIAN ORGANIZATIONS FROM INSTITUTIONAL PERSPECTIVE
}

\author{
Ruth Alas \\ Estonian Business School \\ E-mail:ruth.alas@ebs.ee
}

Received: 20 Oct 2003; accepted 3 Nov 2003

\begin{abstract}
During last decade Estonia has passed through its transition from the authoritarian, centralized, totalitarianism of state socialism, to the democratic country with a free market economy, with different attitudes and values. Estonian companies have been in continuous change process and remarcable part of these changes are deepest by scope - transformational changes. Author proposes that the social phenomena such as organizational change can only be understood in relations to the wider contextual influences that surround them. Changes in Estonian companies could be explained by using institutional and historical context. Research in Estonian companies indicates, that during stable institutions developmental or transitional changes take place in organizations, during societal transience transformational changes occur in organizations.
\end{abstract}

Keywords: Estonian history, Organizational change, Institutionalization

\section{Introduction}

During last decade Estonia has passed through its transition from the authoritarian, centralized, totalitarianism of state socialism, to the democratic country with a free market economy, with different attitudes and values. This type of transition has been described as social transience, in which a complex set of normative and operating principles, embodied in historical structures, systems and practices, becomes replaced by another unknown set, which makes this period for actors very ambiguit and uncertain [1].

Author proposes that the social phenomena such as organizational change can only be understood in relations to the wider contextual influences that surround them. The post-communist transition provides settings, very different in its characteristic, in which discontinuities are more fundamental and change is less constrained by institutional frameworks, which are in process of demolition. During economic transition the challenge has been to internalize a new type of organizational behavior in order to operate successfully under unfamiliar conditions.
Institutionalists have stressed importance of institutional environment to understanding the behavior of organizations. Author argues, that there are connections between the stage of institutionalization in society level and types of changes in organizations. Sahlins argues, that one cannot really understand certain social phenomena without understanding both the historical events and the cultural meanings attributed by the actors to these events [2].

In this paper a brief overview of institutionalism and of theories of change would be given. In order to give socio-economic explanations, which are rooted in the historical and current circumstances of societal and organizational transition, short description about main stages in Estonian history, would be given. This theoretical framework will be followed by an analysis of research results in Estonian organisations.

\section{Transition in society in connections with institutionalism}

According to the institutionalists perspective the functioning of organizations can be described with the 
open-system approach, in which the organization may be seen as answering the challenges of a new environment. Institutions find expression in society through social constructions: formal institutions at the macro level in a market economy include private property and the free market; formal institutions at the micro level are organisations. Individual organisations are under the technical and normative influence of institutionalised environments.

Institutions could be seen from both the structural and social perspective. From a structural viewpoint institutions exist as institutionalised forms of 'external social constraints'. From the social perspective institutions can be understood as operating to enforce behavioural definition, which may take the form of either 'cultural accounts' or 'cultural rules'. This means that institutions are accounts of how the social world works and embody normative principles and social values [3].

Socio-economic transformation, at both macro and micro levels, could be understood as institutional change, from both the structural and social perspective, embracing both structures and social values. The elements of an institution may lose credibility and need redefining - the processes of deinstitutionalisation and reinstitutionalisation take place. During deinstitutionalisation the contingent nature of cultural accounts and rules are revealed, interrogated, contested, opposed, effectively challenged and ultimately overturned. The process may be gradual or sudden and may affect formal institutions and institutional practices at different rates. Deinstitutionalisation takes away the certainty associated with institutionalised rules, attacks the meaningfulness of the social world and thereby reduces the level of social support and motivation.

From this institutional view, social transition may be interpreted as the period between the effective demise of one institutional system and the point at which another institutional system has been established and accepted on new cognitive and normative grounds. Such circumstances create acute social and psychological problem for social actors and this period has been called social transience [1].

Changes in the environment necessitate that organisations modify themselves as well.

\section{Types of organisational changes}

Organisation is a complex system that produces outputs in the context of an environment, an available set of resources, and a history [4].

An effective organisation meets the expectations of multiple stakeholders including shareholders, employees, suppliers, customers, and the society in which it is located. It also demands the loyalty and commitment of these stakeholders to the long-term survival of the organisation and of the social network in which it is embedded [5].

There are several classifications of types of change in the literature on this topic. These types have been compared according to initiation and scope. Most theorists divide change into two groups according to scope: change taking place within the given system, and change aiming to change the system itself.

The most popular terms for this classification are first order change and second order change. First order change provides a method for managing stability. It helps one to manage current strategy more effectively and efficiently [6]. This type of change proceeds via a sequential step-by-step assessment, guided by a specific objective, making systematic and rational evaluations of an organisation and its environment. A first order change cannot produce transformation because it lacks the creativity to discover new strategic ideas [7].

Second order change calls for innovation in order to lead the change. It searches for agreement about what the end result should be and then considers how the organisation could be changed to meet these new expectations. Second order change is difficult to carry out because information gathering in an organisation will tend to reify the rules, culture, strategy and core processes that make up its current paradigm [8].

Transformation calls for a second order change process [9]. First order change stresses growth and single loop learning. Second order change stresses development and double loop learning. In the second order change process change agents should gather information without value judgements. This enables new ideas to emerge [10].

A distinction has been made between incremental change and radical change. Also, the terms linear change and breakthrough change are used with the same meanings. Incremental or linear change occurs within a given system which itself remains unchanged. Radical or breakthrough change changes the system itself. Radical change requires new ways of thinking that alter taken-for-granted and often hidden organisational rules, which limit how people think about change [8]. 
Weick and Quinn use the phrases episodic change and continuous change [11]. Episodic change groups together infrequent, discontinuous, and intentional organisational change. This type of change operates as an occasional interruption or divergence from the equilibrium. It is driven externally and emphasises shortrun adaptations. It tends to occur in distinct periods during which shifts are precipitated by changes to technology or changes in key personnel. The change agent focuses on inertia and seeks points of central leverage.

The phrase continuous change is used for ongoing, evolving and cumulative organisational change. In this concept change is seen as a pattern of endless modifications to work processes and social practice. It is driven by organisational instability. Numerous small accommodations cumulate and amplify. This kind of change is a redirection of what is already under way. Change is cyclical, process orientated, has no targeted end-state, and seeks equilibrium. The change agent is a sense maker, who redirects change. Continuous change emphasises long-run adaptability

If we compare evolutionary change and revolutionary change, evolutionary change is the functional development and growth of an object or system with its core structure remaining essentially intact. It involves incremental modification of the object. Revolutionary change challenges the individual's understanding of objects or systems. This type of change challenges the existing structure and rebuilds a new one [12].

Greiner extended the analogy of individual development to the problems of organisation development and found five development phases through which growing companies tend to pass [13]. The term evolution describes prolonged periods of growth where no major upheaval occurs in organisation practices and the term revolution describes those periods of substantial turmoil in an organisation's life. Evolutionary change is gradual and modifies instead of replacing key practices [8]. During revolutionary change leaders abandon past practices and seek new ones because many old practices are no longer relevant for the new paradigm (ibid). As a company progresses through developmental phases, each evolutionary period creates its own revolution. Rapid change enables the organisation to reach a period of smooth growth and function sooner, thus providing it with a competitive advantage over firms changing more slowly [14]. Long term studies of organisational evolution underscore the revolutionary nature of transformational change [15].

Van de Ven and Poole describe change in organisa- tions using the terms prescribed change and constructive change [16]. The prescribed mode of change creates change within an existing framework thereby producing variations on a theme. It can be compared to first-order change. A constructive mode of change generates unpredictable novel forms that have no continuity with the past. This is similar to second-order change.

Nadler and Tushman divide change according to two criteria: the scope of change and the positioning of change in relation to key external events [4]. According to scope, change can be divided into incremental change and strategic change. This division describes the changing of the subsystems of the organisation versus the changing of the entire system. Strategic change addresses the whole company and helps an organisation develop a completely new configuration. Incremental change focuses upon some components of the organisation with the goal of maintaining or regaining congruence.

According to the positioning of change in relation to key external events, change can be divided into reactive changes and anticipatory changes [4]. Reactive change is the response to an external event or series of events. Anticipatory change is initiated in anticipation of events that may occur. When these two dimensions are combined four types of change are discovered:

- Tuning is incremental change made in anticipation of future events

- Adaptation is incremental change made in response to external events

- Reorientation is strategic change made in anticipation of future events

- Re-creation is strategic change necessitated by external events

The most difficult change to manage is strategic organisational change.

The author argues that in order to describe the changes that have taken place in Estonian companies over the last decades we need more than two types. Ackerman describes three types of organisational change: (1) developmental change, (2) transitional change, and (3) transformational change. Developmental change improves what already exists through the improvement of skills, methods, or conditions [17]. Transitional change replaces current ways of doing things with something new over a controlled period of time. Transformational change means the emergence of a new state, unknown until it takes shape, out of the remains of the chaotic death of the old state. Burke 
and Litwin have developed a model for making a distinction between two types of deeper change [18]. They argue that transformational change occurs as a response to the external environment and directly affects the organisational mission and strategy, the leadership and the culture. Transitional change deals with psychological and organisational variables that predict and control the motivational and performance consequences of the work group climate [18].

Another typology dividing change into three types puts forward Alpha, Beta, and Gamma change. Alpha change is behavioural change, beta change refers to scale calibration, and gamma change is about concept redefinition [19]. Alpha change involves a certain variation in the degree of some existential state, given a constantly calibrated measuring instrument that taps a constant conceptual domain. Beta change involves a variation in the degree of some existential state, complicated by the recalibration of some portion of the intervals of the measurement continuum associated with a relatively constant conceptual domain. Gamma change involves a basic redefinition or reconceptualisation of a certain domain; a radical restructuring of perceived reality that generates differences in state.

Beta change occurs when the standard of measurement used by a subject to assess a stimulus changes from one testing period to another [19]. Gamma change involves discontinuous shifts in mental or organisational frameworks [20]. According to gamma change a subject's understanding of the criterion being measured changes from one testing period to the next. If behavioural change must be considered, then gamma and beta change cannot account for the change on a measurement scale [19].

As it can be seen from these descriptions these two typologies are easily comparable.

In order to compare the different typologies the author has presented types of changes according to different theorists in Table 1.

The author argues that there are connections between the institutionalisation stage at the societal level and types of change in organisations. In Table 2 the author combines institutional stages at the societal level with classifications of the types of change developed by Ackerman described at the beginning of section two [17].

During the stable stage of institutionalisation developmental changes mostly take place. In order to evoke transitional changes additional institutional forms could be added to established institutions. Deinstitutionalisation in society, which starts a period of social transience, calls for transformational changes in organisations. At the same time reinstitutionalisation starts. If reinstitutionalisation is completed then transitional changes start to dominate over transformational.

Table 1. A comparison of change grouped according to scope.

\begin{tabular}{|l|l|l|l|}
\hline & \multicolumn{1}{|c|}{ Growth } & \multicolumn{1}{c|}{ Development } & \multicolumn{1}{c|}{ Transformation } \\
\hline Ackerman (1986) & Developmental change & Transactional change & Transformational change \\
\hline Armenakis (1988) & Alpha change & Beta change & Gamma change \\
\hline Watzlawick et al (!974) & First-order change & & Second-order change \\
\hline Watzlawick et al (1974) & Linear change & & Breakthrough change \\
\hline Watzlawick et al (1974) & Incremental change & & Radical change \\
\hline Greiner (1975) & Evolutionary change & Continuous change & Revolutionary change \\
\hline Weick and Quinn (1999) & Episodic change & Constructive & Van de Ven and Poole (1995) \\
\hline Prescribed & & Nadler and Tushman (1989) & Nadler and Tushman (1989) \\
\hline Reactive change & Anticipatory change & & \\
\hline & Strategic change & & \\
\hline
\end{tabular}

Table 2. Connections between institutionalisation at the societal level and types of change in organisations.

\begin{tabular}{|l|l|}
\hline \multicolumn{1}{|c|}{ Societal level institutionalisation } & \multicolumn{1}{|c|}{ Organisational changes } \\
\hline Stable institutions & Developmental change \\
\hline Creation of additional institutions & Transitional change \\
\hline Social transience (Deinstitutionalisation and reinstitutionalisation) & Transformational change \\
\hline
\end{tabular}


To summarize, changes on society level during economical transition resulted in collapse of structures, systems, rules and principles that had made human behaviour and social life understandable for over fifty years and left a vacuum of meaning. This deinstitutionalization caused changes in organizations and in people's attitudes.

\section{Estonian history from institutional perspective}

In order to provide socio-economic explanations, which are rooted in the historical and contemporary circumstances of societal and organisational transformation, a short description of important stages in Estonian history starting from the first period of independence will be given.

In Table 3 Estonian history has been viewed from an institutional perspective.

During the first period of independence Western values in terms of a work ethic, individualism and free enterprise were adopted in institutions in the field of economy and education [21].

The Soviet occupation in 1940 was followed either by the liquidation of all the civilised institutions characteristic of the Western world, or a restructuring of them according to the principles of the occupant country with the aim of using them in the process of extending communism [22].

In a command economy the institutional structure of the Estonian economy, within the logic of the communist world, was characterised by highly centralised, autocratic elements such as strong price regulation, central control of domestic and foreign trade and enterprise targets that were poorly related to actual demand. Political, economic and other forms of institutional power derive from the same source and operate unidirectionally enabling strong control and a concentration of information. Due to the fact that during the Soviet period the state was responsible for guaranteeing work for everyone enterprises were internally overstaffed and passive, work places were over-secured and attitudes to work were far from ideal [23]. More information about the enterprise culture can be found in Study III.

Reforms began around 1980 with long-term reassignment of parts of state or collective farms to groups organised independently of the central command [24]. In the service sector an analogous development known as contractual task acceptance was also taking place [24].

In the second half of the 1980s enterprises were gradually given more autonomy in the Soviet Union. It became legal to develop small state enterprises, and even international joint ventures, which operated outside the central planning and could be owned by private citizens [25]. It was the first opportunity for the creation of economic incentives.

Radical reforms in Estonia started in 1987-88 when a group of theoreticians and practitioners debated the idea of economic autonomy for Estonia [26]. In 1990 an important change occurred in the strategic aim of the reforms in Estonia: economic autonomy was replaced by independent statehood and the restoration of a market economy [26]. According to opinions held by managers, stability started to increase by 1995 [27].

In 1987 Estonia was at the forefront of reforms in the Soviet Union. In the spring of 1988 over 600 co-operatives were formed in Estonia representing the highest concentration of such enterprises in the Soviet Union.

Table 3. Institutionalisation in Estonian history since 1919

\begin{tabular}{|l|l|l|}
\hline \multicolumn{1}{|c|}{ Period } & \multicolumn{1}{c|}{ Event } & \multicolumn{1}{c|}{ Institutionalisation } \\
\hline $1919-1940$ & Creation of an independent state & $\begin{array}{l}\text { Creation of institutions followed by a period of stable } \\
\text { institutions }\end{array}$ \\
\hline $1940-1950$ & Soviet occupation & Deinstitutionalisation and reinstitutionalisation \\
\hline $1950-1980$ & Under Soviet rule & Period of stable institutions \\
\hline $1980-1987$ & More autonomy for enterprises & Creation of additional institutions \\
\hline $1987-1991$ & IME, movement toward independence & Creation of new additional institutions \\
\hline 1991 & Re-establishment of independent state & Deinstitutionalisation \\
\hline $1991-1995$ & $\begin{array}{l}\text { Transformation from planned economy to market } \\
\text { economy }\end{array}$ & Social transience \\
\hline $1995-$ & More stabilised economic situation, market economy & Reinstitutionalisation, More stable institutions \\
\hline
\end{tabular}


The striving for economic autonomy, which had begun in 1987, gathered force in 1988 and developed into mass political movements for the restoration of independent statehood in each of the Baltic states [28].

During the last decade Estonia has passed through the change from a hierarchical, centralised, system of state-ownership and command planning, to a decentralised, market-driven economy founded on private property and based on different values. This transformation could be described as social transience, in which a complex set of normative and operating principles, embodied in historical structures, systems and practices, becomes replaced by another unknown set making this period for actors very ambiguous and uncertain. Fifty years of Soviet occupation left Estonia with a divergent workforce with differing attitudes toward change both in society and organisations. There are people who have had work experience in vastly different economic systems.

To generalise, the changes in post-soviet organisations have been deeper than those typical of a market economy because the new economic order is based on different attitudes and values and attempts to shift the organisational culture toward new values or beliefs, and this has been considered one of greatest challenges [29]. It has been much easier to transfer technology and change structures than to change culturally embedded practices in transforming countries [30].

From the societal view it is important to point out that during the transformation process the responsibilities of companies were redefined - companies focused solely on economic priorities and renounced their corporate responsibility for providing social services to workers. It makes it difficult for people to accept such a change from being in a secure to being in an uncertain situation. Anxiety and fear caused by this change may hamper organisational learning [31].

Druncker has argued that what is needed is a revolution in managerial culture in Central-Europe - undoing 40 years of the wrong values, incentives and policies [21]. This is also true for Estonia.

\section{Changes in Estonian Organisations}

My approach takes as its central focus the interplay between macro systems and micro behaviour, and it derives from the methodology which places the emphasis on the concrete attitudes of actors, but locates it in the wider social, institutional and historical context.

The author conducted research in 137 Estonian com- panies in the beginning of 2001. The companies represented different industries and were of different sizes [32]. In the research process interviews were conducted with top managers or with members of executive boards about change in their organisations.

The analyses of change taking place in Estonian companies is based on Burke-Litwin's model of organisational performance and change, which helps to make a distinction between transformational and transactional factors. Transformational factors deal with areas that require different employee behavior as the consequence of external and internal environmental pressures, transactional factors deal with psychological and organizational variables that predict and control the motivational and performance outcomes of the climate of the work group [18]. The results of the current survey indicate that transformational factors had changed in $90 \%$ of the companies studied. From this figure we can conclude that changes in Estonian companies were mostly transformational. Following analyses is based on data from Table 4 .

There were more changes in the production sector when compared with the service sector. Ninety percent of production firms had changed strategy compared with $71 \%$ in the service sector. Organisational structure has also been changed more often in the production sector $(83 \%: 75 \%)$. Changes to individual skills were necessary in $75 \%$ of production companies accompanied by system changes in $80 \%$ of companies in the production sector.

The fact that companies in Estonia are quite young should also be taken into consideration. As expected, there had been more changes in companies established before the 90 's than in younger companies. In $87 \%$ of companies, established before the period of transition in society had begun, strategy had changed. Company structure had been changed in $80 \%$ and task requirements in $85 \%$. Organisational culture, which is considered to be very difficult to change, had changed in $56 \%$ of these companies.

The exceptional results in companies established after 1997 was a surprise. These companies had changed their strategy less than the older companies, but $64 \%$ still achieved outstanding results in such a short time. Also, fewer of these companies had changed their mission, only $36 \%$. But to accomplish this mission and to achieve their strategic goals, the organisational culture and leadership were changed, as well as the organisational structure and task requirements. This also necessitated changes in individual skills. As Estonia had experienced an economic crisis, connected with the crisis in Asia and starting at the end of 1997, it 
Table 4. Changes in Estonian organisations based on the Burke-Litwin model.

\begin{tabular}{|c|c|c|c|c|c|c|c|c|c|c|c|c|}
\hline & $\begin{array}{c}\text { All } \\
\text { sample }\end{array}$ & $\begin{array}{l}\text { Sector - } \\
\text { Pro- } \\
\text { duction }\end{array}$ & Service & $\begin{array}{l}\text { Estab- } \\
\text { lished - } \\
90\end{array}$ & 91-94 & 95-97 & 98- & $\begin{array}{c}\text { Number } \\
\text { of emp- } \\
\text { loyees- } \\
25\end{array}$ & $26-50$ & $51-100$ & $\begin{array}{l}101- \\
1000\end{array}$ & $1001-$ \\
\hline$\%$ & 100 & 22 & 78 & 25 & 49 & 20 & 6 & 28 & 19 & 13 & 32 & 8 \\
\hline \multicolumn{13}{|l|}{$\begin{array}{l}\text { Transforma- } \\
\text { tional } \\
\text { factors }\end{array}$} \\
\hline strategy & 75 & 90 & 71 & 87 & 72 & 74 & 64 & 78 & 68 & 79 & 74 & 73 \\
\hline mission & 49 & 53 & 48 & 64 & 41 & 40 & 36 & 38 & 44 & 58 & 51 & 73 \\
\hline culture & 61 & 58 & 55 & 56 & 55 & 49 & 82 & 54 & 47 & 63 & 58 & 60 \\
\hline leadership & 58 & 58 & 58 & 58 & 58 & 51 & 82 & 52 & 50 & 63 & 61 & 73 \\
\hline \multicolumn{13}{|l|}{$\begin{array}{l}\text { Transaction- } \\
\text { al factors }\end{array}$} \\
\hline structure & 77 & 83 & 75 & 80 & 78 & 66 & 90 & 72 & 74 & 83 & 77 & 93 \\
\hline $\begin{array}{l}\text { task } \\
\text { requirements }\end{array}$ & 73 & 73 & 73 & 84 & 65 & 69 & 100 & 72 & 68 & 75 & 68 & 80 \\
\hline $\begin{array}{l}\text { individual } \\
\text { skills }\end{array}$ & 65 & 75 & 62 & 58 & 67 & 51 & 64 & 60 & 65 & 75 & 60 & 73 \\
\hline systems & 64 & 80 & 60 & 71 & 64 & 54 & 64 & 58 & 65 & 58 & 63 & 80 \\
\hline $\begin{array}{l}\text { Management } \\
\text { practices }\end{array}$ & 46 & 45 & 46 & 53 & 44 & 40 & 36 & 28 & 47 & 58 & 49 & 73 \\
\hline
\end{tabular}

could have been that the owners of companies established after these dramatic periods had learned how important it is to be in continuous change in order to remain competitive.

Companies established between 1991-1994 and 19951997, especially in regard to changes in strategy and mission showed relatively similar results. Older enterprises had more often changed structure and individual skills, and organisational culture and management style.

If we analyse companies according to number of employees, more changes have taken place in the biggest companies. Of these companies, $93 \%$ changed structure and $80 \%$ changed task requirements and systems. Strategy, mission and management style was changed in $73 \%$ of companies.

\section{Discussion and conclusions}

According to authors' opinion organizational change can only be understood in relations to the wider contextual influences that surround them. The context for current research was change from hierarchical, centralized, state-ownership systems of command planning, to decentralized, market-driven and founded on private property relations.

To focus on changes in organizations, the author ar- gues, that during Soviet time in companies only some improvement could take place. When Gorbatshov started Perestroika, real changes started to happen, but these changes had to be accomplished in the frames of existing system. Only Estonian separation from Soviet Union started changes changing system itself to new unknown state.

In Table 5 changes in Estonian organizational are presented in institutional context.

Comparison of changes in different industries showed more changes in the production sector when compared with the service sector. This is due to weakness of service sector in Soviet Union, where service departments of big production companies represented service industry. Only around 1980 part of services were allowed to organize into self-organized contractual groups [24].

The same is the problem with small enterprises: there were only big companies in Soviet Union. Only in the second half of the 1980's it became legal to develop small state enterprises [25]. Accordingly there was less need for changes in smaller companies than in bigger ones.

Although after 1995 situation started to stabilize , crises in Asia, which had also impact on Estonian and Russian economy, caused new wave of transformational changes [27]. 
Table 5. Changes in Estonian organizations in institutional framework.

\begin{tabular}{|l|l|l|}
\hline \multicolumn{1}{|c|}{ Period } & \multicolumn{1}{c|}{ Institutionalisation } & \multicolumn{1}{c|}{ Types of organizational changes } \\
\hline $1950-1980$ & Period of stable institutions & Developmental changes \\
\hline $1980-1987$ & Creation of additional institutions & Developmental changes \\
\hline $1987-1991$ & Creation of new additional institutions & Transitional changes \\
\hline 1991 & Deinstitutionalization & Transformational changes \\
\hline $1991-1995$ & Social transience & Transformational changes \\
\hline $1995-$ & Reinstitutionalization,More stable institutions & Transformational changes, transitional changes \\
\hline
\end{tabular}

Results of current survey are consistent with results of an other survey conducted in three former Soviet Republics including Estonia, which indicated that over 40 per cent of the companies studied and which have experienced strategic management change, had encountered not only one but several strategic changes during the years 1989-1997 [23].

To conclude, Estonian companies have been in continuous change process and remarcable part of these changes are deepest by scope - transformational changes. This could be explained by using institutional and historical context. During stable institutions developmental or transitional changes take place in organizations, during societal transience transformational changes occur in organizations.

\section{References}

1. Clark, E.; \& Soulsby, A. Organizational Change in PostCommunist Europe: Management and transformation in the Czech Republic, Routledge, 1999.

2. Sahlins, M. Islands of History. Chicago: University of Chicago Press, 1985.

3. Meyer, J.; Boli, J.; \& Thomas, G. Ontology and rationalization in the Western Cultural Account, in Scott, W. R. et al (eds.) Institutional Environments and Organizations: Structural Complexity and Individualism, London: Sage, 1994, p. 9-27.

4. Nadler, D. A.; \& Tushman, M. L. Organizational Frame Bending: Principles for Managing Reorientation, The Academy of Management, Executive Magazine, 3 (3), 1989, p. 194-204.

5. Kochan, T. A.; \& Useem, M. Transforming Organizations. Oxford University Press, 1992.

6. Bartunek, J. M. The Multiple Cognitions and Conflicts Associated with Second Order Organizational Change. In: Murnighan, J. K. (ed.) Social Psychology in Organizations: Advances in Theory and Research, Prentice Hall, 1993, p. 322-349.

7. Hurst, D. K. Why Strategic Management is Bankrupt.
Organizational Dynamics, Spring, 1986, p. 5-27.

8. Nutt, P. C.; \& Backoff, R. W. 'Crafting Vision'. Journal of Management Inquiry, Vol. 6 (4), 1997, p. 308-329.

9. Watzlawick, P.; Weakland, J. H.; \& Fisch, R. Change: Principles of Problem Formulation and Resolution. New York: Norton, 1974.

10. Pribram, K. I. The Brain, Cognitive Commodities, and the Enfolded Order. In: Boulding, K., \& Senesch, L. (eds.) The Optimum Utilization of Knowledge. Westview Press, 1983.

11. Weick, K.; \& Quinn, R. Organizational Change and Development. Annual Review of Psychology, Vol. 50, 1999, p. 361-386.

12. Dirks, K. T.; Cummings, L. L.; \& Pierce, J. L. Psychological Ownership in Organizations: Conditions under which individuals promote or resist change. In: Woodman, R. W., \& Pasmore, W. A. (eds.) Research in Organizational Change and Development, Vol. 9, 1996, p. 1-23.

13. Greiner, L. E. Evolution and Revolution as Organizations Grow. In: Harvard Business Review On Management. Harper \& Row Publishers, 1975, p. 636-649.

14. Cummings T. G.; \& Worley, C. G. Organization Development and Change, 6th ed., South-Western College Publishing, 1997.

15. Tushman, M.; Newman, W.; \& Romanelli, E. 'Managing the Unsteady Pace of Organizational Evolution'. California Management Review, 1986, p. 29-44.

16. Van de Ven, A. H.; \& Poole, M. S. Explaining Development and Change in Organizations. Academy of Management Journal Review, Vol. 20, 1995, p. 510-540.

17. Ackerman, L. S. Development, Transition or Transformation: The Question of Change in Organizations, Organizational Development Practicioner, December, 1986, p. 1-8.

18. Burke, W.; \& Litwin, G. 'A Casual Model of Organizational Performance and Change', Journal of Management, Vol. 18, 1992, p. 523-545.

19. Armenakis, A. A. 'A Review of Research on the Change Typology'. In: Woodman, R. W., \& Pasmore, W. A. (eds.) Research in Organizational Change and Development, Vol. 2, 1988, p. 163-194. 
20. Golembiewski, R. T.; Billingsley, K.; \& Yeager, S. 'Measurin Change and Persistence in Human Affairs: Types of Changes Generated by OD Designs'. Journal of Applied Behavioral Science, Vol. 12, 1975, p. 133-57.

21. Barnowe, J. T.; King, G.; \& Berniker, E. 'Personal Values and Economic Transition in the Baltic States,' Journal of Baltic Studies, Vol. 23(2) 1992, p. 179-190.

22. Taagepera, R. Estonia - Return to Independence. Westview Press, 1993.

23. Liuhto, K. The Organisational and Managerial Transformation in Turbulent Business Environments - Managers' views on the transition of their enterprise in some of the European former Soviet Respublics in the 1990's, Publications of the Turku School of Economics and Business Administration. Series A-9, 1999 b.

24. Misiunas, R. J., \& Taagepera, R. 'The Baltic States: Years of Dependence, 1980-1986,' Journal of Baltic Studies, Vol. 20 (1), 1989, p. 65-88.

25. Venesaar, U.; \& Vitsur, E. Development of Entrepreneurship, in Lugus, O., \& Hachey, G. A. (Eds.) Transforming the Estonian Economy, Tallinn, 1995, p. 187-207.

26. Taaler, J. 'Economic Reforms: The Main Stages, Programmes and Evaluations', in Lugus, O., \& Hachey, G.
A. (Eds.) Transforming the Estonian Economy, Tallinn, 1995 , p. $1-15$.

27. Liuhto, K. 'The Impact of Environmental Stability on Strategic Planning - An Estonian Study', International Journal of Management, Vol. 16(1), 1999 a.

28. Misiunas, R. J., \& Taagepera, R. The Baltic States: Years of Dependence, 1940-1980. London: Hurst; and Berkeley: University of California Press, 1983.

29. Bluedon, A. C. Time and Organizational Culture, in Ashkanasy, N. M., Wilderom, P. M., \& Peterson, M. F. (Eds) Handbook of Organizational Culture \& Climate, 2000, p. $117-128$.

30. Clark, E. \& Geppert, M. Management Learning and Knowledge Transfer in Transforming Societies: Approaches, Issues and Future Directions, Human Resource Development International, 5(3), 2002, p. 263-277.

31. Schein, E. H. How can Organizations learn faster? The Challenge of Entering the Green Roo', Sloan Management Review, Vol. 34(2), 1993, p. 85-92.

32. Alas, R., \& Sharifi, S. Organizational Learning and Resistance to Change in Estonian Companies. Human Resource Development International, Issues 5.3, 2002, p. 313-331. 